\title{
The Participation of Diverse Faculty and Graduate Students in U.S. Engineering Programs: Implications for Future Agricultural Technology
}

\author{
Edward L Kick* \\ Department of Agriculture and Resource Economics, North Carolina State University, USA
}

Submission: July 26, 2017; Published: August 07, 2017

*Corresponding author : Edward L Kick, Department of Agriculture and Resource Economics, North Carolina State University, USA, Email: elkick@ncsu.edu

\begin{abstract}
Graduate programs in Engineering have immediate applications for the fields of Agricultural Engineering and Technology, but they also are relevant to Rural Development, Agricultural Extension, Soil Science, Food Technology, Forestry and Agronomy, Agricultural Management as well as other fields. Fortunately, due to its importance data are available to generate numerous insights into the top Engineering programs as well as all Engineering programs in the United States. Thus, for example, analyses are conducted here that show the number of women and/or minorities who serve as Engineering faculty and graduate students in top Engineering schools is trivial in proportion to white males. Suggestions are made for remediating this situation. As well, the implications of this situation are discussed by noting some high technology applications of Engineering for contemporary and future agricultural innovations
\end{abstract}

\section{Introduction}

Women are said to now account for about $1 / 3$ of U.S. farm operators, nearing tripling in numbers in the last thirty years. A number will quibble with this figure as being too high, since it includes avocations that are not a common part of the definitional set of "agriculture" adopted by the U.S.D.A. Nonetheless, compared to white men at least, it appears to be the case that women farm on smaller parcels of land, grow diverse crops, and approach farming from a sustainability approach with a higher priority placed on food than they do on raising commodity crops. Speculation abounds as well that they network with one another at higher rates than do male farmers, sharing information critical to successful farming.

In contrast, the U.S.D.A. Census of Agriculture reports that while Black farmers recently have increased in the U.S., there are only 41,024 Black operators on 32,938 farms and ranches. While their numbers have grown by $9 \%$ recently, they still represent only around $1 \%$ of all farmers. The same source notes that the number of Hispanic farmers was 99,734 in the year 2012. This was a 21 increase from 2007. Of all Hispanic farmers 67,000 were principal operators in charge of daily operations.
And in comparison with women and minorities of the 2.2 million farms in the United States, 1.83 million or $86 \%$ of farms have a white male principal operator. There are a myriad of reasons for these relative differences, but an important one is the professional training needed to be successful farm operator in the modern era in industrial and post-industrial societies. The universities in particular channel would-be experts into the fields that feed our country and others. Are universities part of the winnowing process that places white males into positions of prominence in agricultural by virtue of their technical training? In upcoming passages we analyze (primarily) the top 100 Engineering programs in the U.S. to see whether universities are an equalizing force that will augment the strides of women and minorities, or instead are the endpoint in schooling that for the most part reinforces the types of inequities seen above in the agricultural domain.

\section{Sources and Sample}

A circumscribed set of sources was needed for this study. The Moore and Hinis' [1] U. S. News and World Report's [1] treatment of the approximately 100 top Engineering schools is an important

${ }^{* *}$ This work is supported by the USDA National Institute of Food and Agriculture, Hatch Multistate project 1010770 
data source for part of this study. Rankings show the significance of well-known specialty Engineering universities (M.I.T.), eminent institutions in general (e.g., Stanford University), and a number of the formerly named "Big Ten" schools (e.g., Michigan) and counterpart institutions (North Carolina State University). It is unsurprising that the quantity of research expenditures as displayed is the other key resource assumed as important in this report (ASEE, p.35) [2], since they follow rankings rather closely. This relationship likely is causally reciprocal in character and together drives the direction of engineering for the U.S. and for the world. This is true for the use of Yoder's (2012) compilation of data from other sources. A newer version of Yoder's compilation (2015) appeared after analyses reported here were accomplished, but fortunately for this study all changes in raw data led to essentially the same major conclusions. In some cases data for virtually all schools were available.

\section{Overall enrollments}

The composition of the human components of a social institution helps identify its character and future. Enrollment data on engineering programs at the Master's and Doctorate level in all the U.S. yield revealing patterns. Caucasian males substantially predominate at the Master's and Ph.D. levels in engineering degrees attempted and attained, at a level of over $60 \%$ enrolled (Yoder p. 20, 24) [3]. A complication intrudes in the treatment of Asian-Americans with respect to such attainments, which stand at $12.5 \%$ in enrollments, since the "minority" standing of Asian-Americans at variously points has been hotly contested in the U.S. Females are substantially lower in enrollments than males in absolute numbers and proportions (around 23\%--Yoder pp.21-24; 26), followed by Hispanics (6\% Doctoral, 9\% Master's) and African-Americans (5\% Master's, 4\% Doctoral). Since the interaction between students and faculty is a primary concern in student retention and success, and has been expressed particularly as such for minority students, more elaborate data on faculty will be examined next. The data on student graduates reveal some diversity, but the principal group is white males.

\section{Faculty}

African-American faculty represent an absolutely small number of engineering professors (recently about 2.7\% Yoder, p.1) [3], disproportionately concentrated at Historically Black Institutions, and to a significantly degree at moderately-tohighly ranked schools such as North Carolina State University, M.I.T. , Michigan). A similar pattern is visible for Hispanic faculty. Hispanics constitute about $4 \%$ of Engineering Professors, but there are fully 174 tenured/tenure track Hispanic faculty at the University of Puerto Rico, Mayaquez and the Polytechnic University of Puerto Rico. When the relatively small numbers of minority faculty at other top universities are examined, it is apparent, unfortunately, that many faculty are physically unavailable to serve students at other, key U.S. institutions.
Women constitute $14 \%$ of engineering faculty as a whole. At the top 100-ranked research institutions, aside from the University of Washington (ranked $27^{\text {th }}$.), women do not broadly cover the top institutions of higher learning (Yoder, p. 30) [3]. True, at over 50 universities they represent over $17 \%$ of the Engineering faculty, but even among schools where they are in the $17-20 \%$ range very few of these schools are among the 100 top-rated programs in engineering. According to Yoder's data (p.30) [3], in terms of the sheer numbers these reflect, at the top, 67 women (Georgia Institute of Technology), 63 women (M.I.T.), and 61 women (University of Maryland). Were we to cumulate all female faculty among the 29 universities with the most female engineering faculties the count would total to 792 . More positive interpretations appear if trend data are analyzed, since the percentage of women is up from $8.9 \%$ of the total in 2003 to $14 \%$ in 2012 .

\section{Sub-disciplinary analysis}

For doctoral degrees in engineering awarded overall during the recent period, most Doctoral degrees in engineering were awarded in Mechanical Engineering (1323), Electrical/ computing (1197), and Chemical and Computing Science. This breakdown is informative when compared with the choices selected by females. Their preferences in the immediate period were Civil/Environmental (39.1\%), Environmental (36.6), and Biomedical (36.2) engineering. Further comparisons are made difficult because breakdowns are alternately given in numbers and percentages, instead of a uniform metric. These interests are especially useful later in discussions of the future compositions of engineering as a discipline and agriculture as an occupation. Taking a liberty with inference, advanced female engineering students have an over whelming desire to put humanity and the global niche surrounding us into a more desirable state. Even primarily economic institutions such as the World Bank agree what many refer to as "sustainability" as the top priority now and well into the future. The environment takes center stage in sustainability discussions.

\section{Engineers as teachers}

Yoder [3] counts over 25,000 professors of engineering. Again, close to two-thirds of this faculty are white men. Full professors have predominated among whites $(\mathrm{N}=8,838)$, followed by white Associate Professors (4378) with Assistants dominated by whites as well $(\mathrm{N}=2,793)$. Asians dominate thereafter, holding 6,200 positions. Hispanics are in 973 engineering oppositions, and blacks are in 639 seats in the engineering professoriate. The obverse holds for women, who again comprise around $20 \%$ of engineering faculty. Assistant professors predominate $(22.8 \%)$, followed by associates (16.2), and full professors (8.7\%). These structural patterns may or may not continue deep into the future. Despite ASEE's (2) occasionally expressed optimism, backed by gradual increases in overall numbers when compared with the not- too- distant past, only long- term changes in such trends would be reassuring. This could be motivated by changes in the disciplines' intervention into societal programs meant to 
augment the perceived viability of engineering careers by girls, and by changes in the structure in the discipline itself. As is, only a fractional proportion of women and especially minorities will control our nation's future engineering needs. These needs require careful examination-they may predominate in treating the aged and limiting what now is the destruction of earth at a rate that is approximately 1.5 times its recovery rate.

\section{Breakdowns by racial groupings}

African American faculty represent circa $2.7 \%$ of the professoriate in engineering (Yoder, p. 33) [3]. Close to $4 \%$ elect mining as their specialty, and about 3\% choose general Engineering, Civil Engineering, Biological and Cultural Engineering, Mechanical Engineering and Computer Engineering. Remaining data show only a gradual drop-off in interest areas, down to a $1.1 \%$ figure for Computer Science (outside). Among Blacks 2\% are Full Professors, 3.2\% are Associate Professors, and $3.4 \%$ are Assistant Professors. The pattern for Hispanics resembles the pattern for Blacks in some respects. For all engineering faculty Hispanics represent 3.9\%. Among Hispanics $4.5 \%$ are at the Assistant rank, $4.6 \%$ at the Associate rank, and $3.1 \%$ are Full Professors. They too chose a variety of subdisciplines (for data to this point see Yoder. p. 33). But what is of greatest interest in many ways is the patterns shown for Asians. Fully 29\% of Asians are at the Assistant level, $25.2 \%$ are at the Associate level and $22.2 \%$ at the Full Professor level. While the pattern of occupancy at the lower ranks remains for all minority groups, for Asians, so many are already at the higher rank levels that they are in advantageous positions where they may effectively serve as mentors for their beginning colleagues. This clearly is not the case for the Hispanic and Black groupings. Base numbers are suggestive as well. It is worth repeating that the Yoder data show that of the over 12,000 Engineers in the Professoriate, 8000 are white (only 9\% female), 3000 are Asian, less than 400 are Hispanic, and less than 300 are African American. Among Associates 4378 are white 1825 Asian, 335 are Hispanic and 251 are African American. Among Assistants 2793 are White, 1609 are Asian, 246 Hispanic and 187 African American [3]. For females close to $9 \%$ are Full Professors, 16 percent are Associates and around 23\% are Assistants. Over time data (pp. 42-43) indicate very few changes to the numbers treated thus far, although all numbers have increased marginally with time. Marginal changes indicate no convincing institutional commitment to improving the lot substantially for any marginalized group. Further, among minorities degrees are sought across a broad set of areas, and when coupled with the sheer lack of numbers this guarantees little by way of in-group camaraderie that might be formed in other groups

\section{Graduate data: concentration choices}

It is possible that the Discipline of Engineering will take on a very different complexion due to social forces in upcoming decades. For instance, 51.4\% of Master's in Engineering are held by women at Yale University and over 33\% of Master's degrees are held by women at eleven other institutions. Similarly, 39.3\% of Ph.D.'s in Engineering is held by women at Syracuse, and over $33 \%$ at nine other institutions. Certainly, as well, women will be a major force in Environmental Engineering in the future. Recall that nearly $40 \%$ of women elected to focus upon Environmental Engineering, and over $30 \%$ chose a variant of this concentration. According to the Bureau of Labor Statistics (2015), environmental engineers use the principles of engineering, social science, biology, and chemistry, to develop solutions to environmental problems. They improve recycling, waste disposal, public health, water, and pollution.

In contrast a prime choice for men is mechanical engineering, which "designs, develops, builds and tests mechanical and thermal sensors and devices, including engines and machines" (Bureau of Labor Statistics [4]. The annual wage is slightly lower for mechanical engineers than environmental engineers, but it is understandable why so many white male graduates choose this line of expertise. They literally were trained into this type of career from a very early age with the presents and gifts they were given as youngsters. Indeed, there is an irony worth mentioning here. As currently practiced building and construction ("mechanical") are the number one producers of waste (and related pollution) in the world, and the practices of environmental engineers are precisely the mechanism for undoing their damage!

\section{Implications of trends in gender and minority standing}

Very few women and minorities enter the world of engineering relative to white men. Similarly, very few white (black or Hispanic) men now enter the world of primary education or nursing, which are trends rarely discussed by the public, but unfortunate tragic nonetheless. The stereotyping of people and of what should constitute the contours of disciplines is unfortunate. These are complex issues, well beyond this analysis. However, in the present case, it would NOT be an unwarranted suggestion to change the character of the discipline of Engineering to substantially open it to women and minorities. Even the definition of what it means to be an "Engineer" might be changed so that the engineering toys children play with draw in a much wider audience. Most have heard of "Barbie and Ken" stereotyping, and it could be argued the preparatory toys children receive with respect to engineering propel children of different genders and racial/ethnic groupings into different career trajectories at a very early age. It would be a very interesting investigation to determine how many crane operators or frontend loader drivers and designers of such machinery are depicted as black men or white women. Changing toys, of course, is just one step in the changing of the socio-demographics of engineers.

Beyond this we all remember the sorts of parents and children and teachers depicted in early readers, and then later in the texts used in middle-school though high school, even through college. This is speculative but the same sort of typing occurs in depictions there as it does in the play of children. True, "sensitivities" run much higher now than when we were children, but it still would be worth a concerted research effort to discern any (un)conscious bias in the presentation of the genders and the 
races both in generic books that treat a variety of subjects and in other specialty books that probably reflect more accurately the real world composition of different occupations.

However, real changes might also occur directly at the tertiary education level. If would be an interesting albeit controversial experiment to violate students' classroom expectations and then examine their reactions. For instance in a school that is not known for its Hispanic populations, use Hispanic instructors on the first day of class, and then judge student responses. There are a nearly infinite number of possible combinations of this sort of experiment, but I do not recall reading about any whole scale experiment of this nature in the scientific literature.

Let us consider as well accompanying and real "cluster hires" to offer the delivery of such a curriculum by qualified non sociodemographic "appropriate" others. A long-term experience would yield fascinating results for study. If done for real, it would change the nature of what engineering is at the target school.

It has been suggested that by improving the species "richness" at universities, we can create a more adaptive society, which improves its survival chances relative to others. At the moment World Bank data suggest we are moving in the opposite direction on key indicators-natural capital (environment), financial capital, human capital, and infrastructural capital, in particular.

What would greater true diversity offer? Much of this is "old hat," but the introduction of greater diversity into Engineering and into the academy as a whole, including the faculty and graduate programs, might improve our ability to innovate broader solution sets, which to innovate broader solution sets, which today are constrained by homogeneity in solutions sets. Creativity in ideas generally is constrained by the exclusive nature of inter-group relations. Flexibility in response, since many responses are, in fact, gender and race- graded. Readiness to address outside challenges, since there is a palpable fear between the genders and the races (which often is the subject of television sitcoms, which depict its consequences with some realism). Less susceptibility to "groupthink," which stems from fear of "outgroups," and near exclusive dealings with other "ingroup" members? Greater degree of flexible organizational ability-the bureaucratic configurations that would evolve would differ if they were constructed by different gender and races. This package of abilities is not additive, but rather multiplicative. Put a different way, each does not add to the size of a final product; instead it multiplies its way through to a much larger and interactive final product.

This study has identified numbers and percentages of groups in the faculty and graduate student bodies in engineering across the U.S. universities that show large disparities in group membership that require remediation. Why is remediation required? It is likely that Darwinian principles apply. Nearhomogeneity of socio-demographics and thought reign, when heterogeneity or diversity has been the past key to our successes as a nation. The U.S., as a remaining world hegemon, is on the slide in global power and in our set of national capitals. By more open and diverse deeply involved thought and debate, broadbased cultural arrangements might advance the knowledge and application base in a number of disciplines. It might spawn more of the type of engineering applications in agriculture that have recently emerged or are likely to be fully operational in the not too distant future.

For example, Data Policy Horizons Canada worked with futurist and data visualizer Michell Zappa of envisioning to produce a report called Meta Scan 3: Emerging Technologies and accompanying info graphics. A reproduction of selected passages from that summary for emerging agriculture technologies provides some illustrations. The originals in complete form can be found at: www.pbslearningmedia.org

Consider the following long, but useful quotation selectively lifted from that report: "Below are technologies related to agricultural and natural manufacturing under four key areas of accelerating change. Sensors, Food, Automation and Engineering.

Sensors help agriculture by enabling real-time traceability and diagnosis of crop, livestock and farm machine states. Food may benefit directly from genetic tailoring and potentially from producing meat directly in a lab. Automation will help agriculture via large-scale robotic and micro-robots to check and maintain crops at the plant level.

Engineering involves technologies that extend the reach of agriculture to new means, new places and new areas of the economy. Of particular interest will be synthetic biology, which allows efficiently reprogramming unicellular life to make fuels, byproducts accessible from organic chemistry and smart devices.

We have included predictions based on consultation with experts of when each technology will be scientifically viable.

\section{Sensors}

Livestock biometrics: Collars with GPS, RFID and biometrics can automatically identify and relay vital information about the livestock in real time. Scientifically viable in 2017; mainstream and financially viable in 2020 .

Crop sensors: Instead of prescribing field fertilization before application, high-resolution crop sensors inform application equipment of correct amounts needed. Optical sensors or drones are able to identify crop health across the field (for example, by using infra-red light). Scientifically viable in 2015; mainstream in 2018; and financially viable in 2019.

\section{Food}

Genetically designed food: The creation of entirely new strains of food animals and plants in order to better address biological and physiological needs. A departure from genetically modified food, genetically designed food would be engineered 
from the ground up. Scientifically viable in 2016; mainstream in 2021; and financially viable in 2022.

\section{Automation}

Variable rate swath control: Building on existing geolocation technologies, future swath control could save on seed, minerals, fertilizer and herbicides by reducing overlapping inputs. By precomputing the shape of the field where the inputs are to be used and by understanding the relative productivity of different areas of the field, tractors or "agbots" can procedurally apply inputs at variable rates throughout the field.

Scientifically viable in 2013; mainstream in 2014; and financially viable in 2016. Agricultural robots: Also known as agbots, these are used to automate agricultural processes, such as harvesting, fruit picking, ploughing, soil maintenance, weeding, planting, irrigation, etc. Scientifically viable in 2018; mainstream in 2020; and financially viable in 2021.

Robotic farm swarms: The hypothetical combination of dozens or hundreds of agricultural robots with thousands of microscopic sensors, which together would monitor, predict, cultivate and extract crops from the land with practically no human intervention. Small-scale implementations are already on the horizon. Scientifically viable in 2023; mainstream and financially viable in 2026 .

\section{Engineering}

Closed ecological systems: Ecosystems that do not rely on matter exchange outside the system. Such closed ecosystems would theoretically transform waste products into oxygen, food and water in order to support life-forms inhabiting the system. Such systems already exist in small scales, but existing technological limitations prevent them from scaling.

Scientifically viable in 2015; mainstream in 2020; and financially viable in 2021. Synthetic biology: Synthetic biology is about programming biology using standardized parts as one programs computers using standardized libraries today. Includes the broad redefinition and expansion of biotechnology, with the ultimate goals of being able to design, build and remediate engineered biological systems that process information, manipulate chemicals, fabricate materials and structures, produce energy, provide food, and maintain and enhance human health and our environment. Scientifically viable in 2013; mainstream in 2023; and financially viable in 2024. Vertical farms. Stefano Boeri Architetti.

Vertical farming: A natural extension of urban agriculture, vertical farms would cultivate plant or animal life within dedicated or mixed-use skyscrapers in urban settings. Using techniques similar to glass houses, vertical farms could augment natural light using energy-efficient lighting. The advantages are numerous, including year-round crop production, protection from weather, support urban food autonomy and reduced transport costs. Scientifically viable in 2023; mainstream and financially viable in 2027."

This selected list shows a truly short list of interrelationships between contemporary engineering and technological innovations that can significantly affect agricultural production. It is certain that most would agree that in these cases engineering has useful impacts on the production and profit of food generation and sales. There is no way of knowing how much that helps us in predicting how the list might change and blossom if human variety in Engineering programs were altered so that women and minorities were far more instrumental in fashioning the field of Engineering. But speculation is in order. It is noteworthy that a handful of innovative applications include not just yield and profit emphases, but an emphasis on helping to improve the environment surrounding us.

However, recall the clear preference of women in engineering programs for applications that had environmental components. It is probable that if historically male sub-fields of Engineering adopted a heavier environmental component they would attract more qualified females. Given the contemporary emphases now emerging on most college campuses in "sustainability" and environmental issues, it is reasonable to assume that Engineering as a field would increase rather substantially its overall pool of applicants including qualified minorities and white males. This logic also suggests that newly minted Ph.D.s will include greater numbers of women and minorities bound for faculty positions around the nation. These curricular changes can be considered immediately, but there also can be some confidence that they will be inevitable over the longer run.

Finally, consider the changes that this agenda will bring to the way agriculture is done. It likely will accelerate the pace of urban gardens and small organic farming. Moreover, as the earlier list suggests there will be greater change in related fields such as chemical and biological engineering, as well as mechanical engineering. Imagine crop-related field machinery that improves quality and quantity of yield while ensuring more favorable inputs to and outputs from the production and harvesting process.

\section{References}

1. Robert M, Kenneth H (2015) Engineering Schooling Rankings. U.S. News and World Reports, Washington, USA.

2. ASEE Report (2015-2016) American Society for Engineering Education, Washington, USA.

3. Brian Y (2012) Profiles of beginning teaching colleges. American Society for Engineering Education, Washington, USA.

4. Bureau of Labor Statistics (2016-2017) Occupational Outlook Handbook Outlook: Mechanical Engineer. US Department of Labor Washington, USA. 


(C) This work is licensed under Creative
Commons Attribution 4.0 License
DOI: $10.19080 /$ ARTOAJ.2017.09.555761

\section{Your next submission with Juniper Publishers will reach you the below assets}

- Quality Editorial service

- Swift Peer Review

- Reprints availability

- E-prints Service

- Manuscript Podcast for convenient understanding

- Global attainment for your research

- Manuscript accessibility in different formats

( Pdf, E-pub, Full Text, Audio)

- Unceasing customer service

Track the below URL for one-step submission https://juniperpublishers.com/online-submission.php 